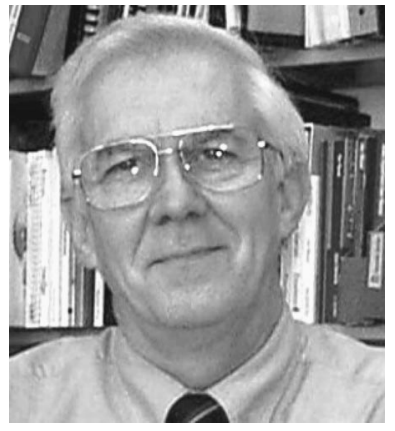

\section{How To Make Yourself Invisible}

Two years ago I described optical engineers as invisible professionals (April 2001 Editorial: "The refractive index of optical engineers is one"). This was a commentary on the absence of our profession in lists of job classifications and its exclusion from Standard Occupational Codes (SOCs). But, if you still feel reasonably substantial and solid, not a hint of transparency about you, I have to tell you that you and some of your colleagues have found a way to disappear...at least, professionally.

Once upon a time it was considered the duty of any researcher to stroll over to the library and spend an afternoon scanning the contents of the journals. That's why many of the journals put their table of contents on the front cover. Beyond the stroll, the point of this exercise was to allow a researcher to keep up with what was happening in his or her field. Then Current Contents arrived on the scene and the perusing could be done in the office. But the evaluation of the papers was delayed until you could get over to the library. Things have progressed to the point where Current Contents can be obtained via the Internet, on a diskette or CD-ROM, or by FTP (file transfer protocol). Or, in my case, I get onto GALILEO (GeorgiA LIbrary LEarning Online) and mouse my way into Current Contents Connect, an online version that is accessible by anyone at a Georgia educational institution.

So, it's been a while since I've been over to the library. But the staff over there has been hard at work providing me with resources and pathways to find the information I need at the click of a mouse. Will I find you there? I don't mean at the Georgia Tech library. Rather, if I go to the databases provided to me by Tech and I look for your work using Current Contents Connect or the Engineering Index or the INSPEC ${ }^{\circledR}$ database, will I be able to find you?

Most authors today seem to have little appreciation of the fact that how they construct the title of their paper and select the keywords that describe it can have an impact on its acceptance. Your paper is only as visible as you make it. By choosing words for the title, the abstract, and the keywords, you make it easier for those who may be interested in your paper to be able to find your work.

This might seem trivial, but I submit it might be a matter of professional life and death. Consider that as citations of your work in other papers become more and more important (see last month's editorial, "Web of Science"), the ability for those working in your field to find, appreciate, and cite your works becomes crucial.

Most people probably think they do a pretty good job of describing their work in titles and keywords. I happen to be in a unique position to determine this. Every month before this journal goes to press, the staff at SPIE sends me a file consisting of the first page of all the papers that will appear in the journal that month. It is my job to determine the category for each paper. These categories then appear on that month's cover and serve as the headings for the sections in the Table of Contents. So how do I determine the categories? First, I look at the keywords the authors provided and then I look at the title. In a fair number of cases, the category is easy to determine from these items. But for too many papers, I haven't a clue. Sometimes I have to read the paragraphs of text on that first page to gain some idea of what the paper is about. Many authors apparently have no idea how to describe their own work.

The worst example of this occurred the other day. I had just received a manuscript in the area of telecommunications. The abstract was certainly abstract enough, but the payoff was the list of six keywords: "PON, MAC, OLT, ONU, Optical Network." I figured out the last one OK, but for the life of me, I have no idea what the others mean. Perhaps that's what telecom researchers look for. But I rather doubt these keywords will signal the content of their paper to others.

So what should someone submitting to Optical Engineering do?

Take some time and think about what your paper is "about." Try to separate the results of the paper, as compelling as they may be, from the area you are studying, the techniques you are using, and phenomena that you are investigating. Try to include one general term, such as "interferometry," "image processing," or whatever is appropriate. Next, select one or two terms that narrow the focus to the topic that you are addressing. Finally, add specific terms that define the experiment.

Then... maybe I'll be able to see you, if I come looking.

Donald C. O'Shea Editor 